\title{
Technique
}

\section{A modified cannula for sampling pancreatic juice in the dog}

\author{
A. N. FAWCETT From the Department of Surgery, \\ Royal Infirmary, Sheffield
}

Acute experiments in animals to obtain pure and total collections of pancreatic juice by securing a cannula in the main pancreatic duct are of limited value as pancreatic function may be altered by the anaesthetic agents or by the operative procedures and tests cannot be repeated in the same dog. Intubation of the pancreatic duct through a duodenal cannula in chronic fistula dogs may be difficult and, owing to the anatomy of the duct systems, it is difficult to ensure Received for publication 9 September 1969.

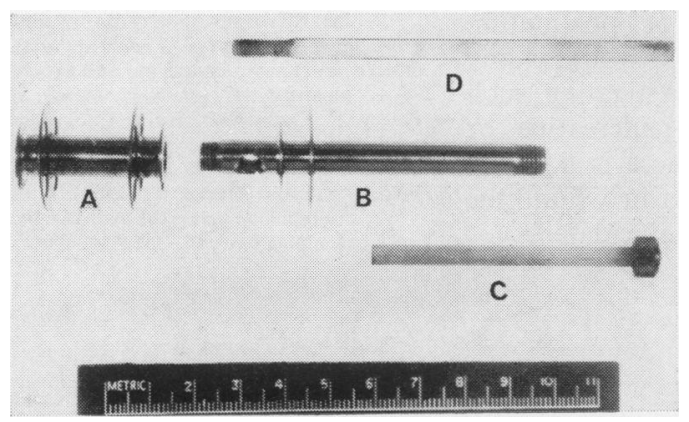

Fig. 1 The component parts of the cannula.

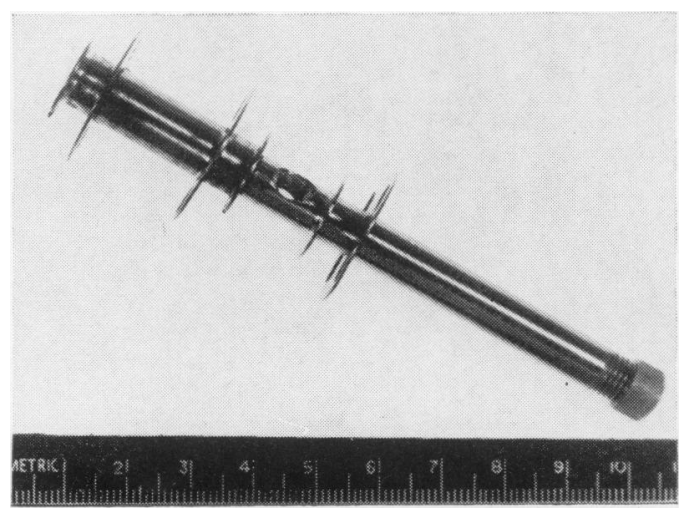

Fig. 2 The cannula assembled.

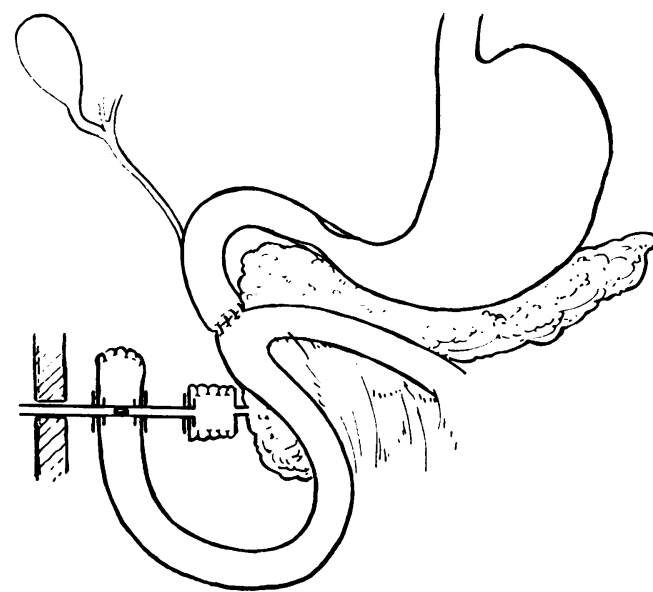

Fig. 3 Diagram illustrating the position of the cannula and the sites of anastomosis.

that all the juice is being collected. There is often leakage around the cannula and the cannula may be relatively easily dislodged by peristaltic movements of the duodenum.

\section{New Cannula}

To simplify the process of collection of juice a new cannula has been designed (Figs. 1 and 2). Section $A$ is used to connect the pouch to the duodenum and is essentially similar to the modified cannula used by Stenning (1969). Section B is a second cannula whose function is to connect cannula $A$ to the exterior; the end of this section is threaded so that it can be screwed into A. The shaft bears two flanges which lie inside and outside the duodenal wall. Between the smaller flange and the threaded end of the cannula a large hole is bored through the shaft. This hole lies within the duodenum and allows the pancreatic juice to drain out of the pouch into the lumen of the bowel. $C$ is a plug and cap which is screwed into $B$ and reaches to the edge of the transverse hole. It prevents escape of juice to the exterior. $D$ is a rigid cannula with a thread at one end. It passes freely into cannula $B$ and is screwed into the shaft of cannula $A$. When the animal is to be tested the presence of this tube prevents juice flowing into the duodenum and allows total collection.

\section{Operative Procedures}

The dog's abdomen is opened through a midline incision and the duodenum and pancreas are mobilized. The main pancreatic duct is identified and the accessory duct, which usually enters the duodenum close to the orifice of the common bile duct, is identified and divided between ligatures. The duodenum is then divided transversely between the common bile duct and the main pancreatic duct and also at a suitable distance (about $1.5 \mathrm{~cm}$ ) distal to the pancreatic duct and the intervening segment is closed to form a pouch into which the pancreatic juice is discharged. The end 
of the distal portion of the duodenum is closed and the proximal duodenum is anastomosed end to side to the intestine in the region of the duodeno-jejunal junction. It was considered that this arrangement would be preferable to anastomosing the duodenum in continuity since the cannula traverses the lumen of the duodenum and might obstruct it (Fig. 3).

A hole is made in the antimesenteric border of the duodenal pouch and one end of cannula $A$ inserted and secured with a purse string suture around the stem of the cannula. The wall of the pouch is also sutured to the large flange. The other end of the cannula is inserted through a hole in the side of the closed duodenal stump and similarly secured. The end of cannula B is then passed through a hole in the opposite wall of the duodenal stump and it is screwed firmly into cannula A. A purse string suture secures the duodenal wall around the cannula and other sutures secure it to the wide flange. The stem of the cannula is then brought out through the abdominal wall at a suitable site. A third cannula is inserted into the stomach and brought out through the abdominal wall to the left of the midline. The abdomen is then closed in layers.

\section{Experience with the Cannula}

Two dogs have been prepared with this type of cannula. Both dogs had an uneventful postoperative course and were in excellent health four months later. The cannula system has remained watertight to pressures up to $80 \mathrm{~cm}$ saline. Each has been the subject of 16 experiments. In a series of tests in which the dogs were given constant-rate infusions of secretin over short periods of time (quarter to one hour) the flow rates were found to rise with increasing dosage and the dose response curves show close agreement between flow rates in separate tests at any given dosage.

I wish to thank Mr F. D. Naylor for his invaluable help in preparing the experimental animals and in the experiments themselves, Professor H. L. Duthie and Dr K. G. Wormsley for their advice and encouragement, and Mrs A. Berney for secretarial assistance.

\section{Reference}

Stening, G. F. (1969). A modification of a chronic pancreatic fistula in the dog. Brit. J. Surg., 56, 308-310.

\section{The May 1970 Issue}

\section{THE MAY 1970 ISSUE CONTAINS THE FOLLOWING PAPERS}

Studies on intestinal absorption of amino acids and a dipeptide in a case of Hartnup disease

F. NAVAB AND A. M. ASATOOR

Intestinal absorption of two dipeptides in Hartnup disease

A. M. ASATOOR, B. CHENG, K. D. G. EDWARDS, A. F. LANT, D. M. MATTHEWS, M. D. MILNE, F. NAVAB, AND A. J. RICHARDS

The neurological lesion in achalasia of the cardia BARBARA SMITH

The effects on human gastric secretion of prolonged continuous intravenous infusions of maximal and supramaximal doses of histamine acid phosphate and pentagastrin

D. A. AUBREY

Effects of histamine acid phosphate and pentagastrin on gastric secretion in normal human subjects D. A. AUBREY AND A. P. M. FORREST

Recurrent ulcer after vagatomy and pyloroplasty: the $x$-ray appearances and their value in diagnosis J. ALEXANDER WILlIAMS AND D. S. M. TOYE
Experiences with a rat bio-assay in the diagnosis of the Zollinger-Ellison syndrome CHRISTINE G. THOMSON, I. G. M. CLEATOR, AND W. SIRCUS

Abnormal metabolism of secondary bile acids in patients with cirrhosis $Z$. R. VLAHCEVIC, I. BUHAC, C. C. BELL, JR., AND LEON SWELL

Liver in haemoglobin $\mathbf{H}$ disease CHEW BENG KENG AND TAN KHENG SHOO

Cholelithiasis: A clinical and dietary survey MARY WHEELER, LOIS LOFTUS HILLS, AND BETTY LABY

Failure of the human rectum to absorb electrolytes and water GHISLAIN J. DEVROEDE AND SIDNEY F. PHILLIPS

Ultrasound in the diagnosis of malignant pancreatic tumours G. ENGELHART AND U. W. BLAUENSTEIN

\section{Progress Report}

The chemical composition and function of gastrointestinal mucus J. SCHRAGER

Notes and activities

Copies are still available and may be obtained from the PUBLISHING MANAGER, BRITISH MEDICAL ASSOCIATION, TAVISTOCK SQUARE, W.c.1. price 17s. 6D. 